\title{
Contato com Antígenos Paternos pela Mucosa Vaginal e Oral e 0 Aborto de Repetição
}

\author{
Contact with Paternal Antigens in Oral and Vaginal Mucosa and Recurrent Abortion \\ Rosiane Mattar, Regina Victoria Pereira Soares, Luiz Camano, Silvia Daher
}

\begin{abstract}
RESUM0
Objetivo: determinar se a prática do sexo oral e vaginal, com ou sem exposição ao ejaculado, diminui a ocorrência de abortamento recorrente.

Método: estudo caso-controle desenvolvido entre maio de 2000 e abril de 2003. Foi aplicado questionário no qual foram assinaladas algumas características de antecedentes clínicos, obstétricos e sexuais da mulher. Foram constituidos dois grupos de estudo: grupo caso, com 116 mulheres com antecedente obstétrico de dois ou mais abortamentos espontâneos, sem a ocorrência prévia de gestação acima de 22 semanas, e grupo controle, com 241 mulheres cujo antecedente obstétrico mostrasse uma ou mais gestações a termo com filho vivo e sem a presença de abortamentos. As variáveis analisadas relacionaram-se ao número de parceiros com os quais a mulher manteve relações sexuais, uso rotineiro de preservativo masculino, prática de sexo oral e exposição da mucosa oral feminina ao material ejaculado.

Resultados: relataram somente um parceiro 38,8\% das mulheres do grupo caso e 35,7\% das do grupo controle. Em ambos os grupos cerca de 75\% das mulheres relataram que seus parceiros não usavam rotineiramente preservativo. Aproximadamente 55\% das mulheres de ambos os grupos referiram que praticavam sexo oral, sendo que 13,8\% das com aborto de repetição e 20,3\% das com história de sucesso gestacional o faziam com exposição da mucosa oral ao ejaculado. Não houve diferença entre as pacientes com aborto de repetição e as com sucesso gestacional quanto ao número de parceiros, uso de preservativo, prática de sexo oral e exposição da mucosa oral ao ejaculado pelo parceiro.

Conclusão: nossos resultados não confirmam a hipótese de que o comportamento sexual tenha influência sobre a ocorrência do aborto espontâneo de repetição.
\end{abstract}

PALAVRAS-CHAVE: Aborto espontâneo de repetição. Aloimunidade. Comportamento sexual.

\section{Introdução}

Abortamento é a eliminação do concepto antes de sua viabilidade haver sido adquirida. É evento frustrante, principalmente quando a gravidez é desejada. Felizmente, costuma ser ocorrência isolada, e os sentimentos de tristeza dos

Departamento de Obstetrícia - Universidade Federal de São Paulo - UNIFESP - EPM

Correspondência:

Rosiane Mattar

Rua Desembargador do Vale 81, apto. 21-B - Perdizes

05010-040 - São Paulo - SP

e-mail: rosiane.toco@epm.br pais são minimizados por gestações subseqüentes que transcorrem normalmente. Existe, entretanto, um grupo de casais que aborta repetidas vezes, nos quais observa-se que, a cada perda gestacional, aumentam os sentimentos de pesar e frustração. Cerca de $2 \%$ dos casais sofrem dois e 0,4\% deles apresentam três abortos consecutivos $^{1}$.

Apesar de todo o progresso que observamos na Medicina nas últimas décadas, em considerável porcentagem dos casos de perda gestacional recorrente não se consegue determinar uma causa e estabelecer tratamento que garanta solução do problema². 
Em grande número dos casais com aborto espontâneo de repetição (AER) encontra-se uma ou mais anomalias, embora seja dificil comprovar sua relação com a repetição do aborto. Entre os fatores que podem ser relacionados ao quadro estão os cromossômicos, imunológicos, endócrinos, anatômicos, trombóticos, infecciosos, ambientais e psicológicos ${ }^{2}$.

Um dos fatores que é mais estudado e pesquisado, na atualidade, no intuito de esclarecer casos em que a investigação de outras causas não permitiu qualquer conclusão, é o imunológico. Neste aspecto estão envolvidos os fenômenos auto-imunes e os aloimunes.

O mecanismo auto-imune se caracteriza pela produção, por parte do sistema imunológico materno, de auto-anticorpos que vão alterar o leito placentário e com isso determinar a perda gestacional $^{3}$. No fenômeno aloimunológico estão implicados distúrbios no reconhecimento dos antígenos (Ag) fetais de origem paterna e/ou no desencadeamento de resposta imunológica materna moduladora e protetora ${ }^{4}$.

Ainda não há explicação definitiva para o fato de o organismo materno aceitar o desenvolvimento do concepto durante os nove meses da gestação, o que representa um dos maiores paradoxos imunológicos. O sistema imunológico tem a função de reconhecer como estranho e de elaborar mecanismos para rejeitar todo enxerto de órgãos de doadores que não sejam geneticamente idênticos ao receptor. O feto possui Ag de origem paterna, sendo considerado, portanto, pelos conceitos imunológicos, um aloenxerto que deveria ser rejeitado. Representa, entretanto, exceção a esta regra.

Primordialmente a aceitação do feto pelo organismo materno foi atribuída à ausência de resposta imunológica materna. Medawar ${ }^{5}$, para justificar esta condição, elaborou algumas hipóteses. Estas incluem: o feto seria imunologicamente neutro; o útero seria local imunologicamente privilegiado; a placenta funcionaria como barreira separando a mãe de contato com o feto e o estado de imunossupressão da gestante.

Estas hipóteses foram contestadas por inúmeras investigações nas quais se demonstrou que durante a gravidez existe o desencadeamento de resposta imunológica materna contra Ag fetais, envolvendo a participação de fatores humorais e celulares. Como esta resposta é potencialmente agressiva ao feto, para que não ocorra rejeição é essencial que, concomitantemente, seja desencadeada resposta imune protetora ${ }^{4}$.

$\mathrm{Na}$ gravidez normal, o sistema imunológico materno reconheceria os Ag feto-paternos no sinciciotrofoblasto. Entretanto, ao contrário dos mecanismos aloimunológicos clássicos, parece que esse reconhecimento estaria mais associado ao desenvolvimento da imunotolerância materna do que aos mecanismos de rejeição ${ }^{6}$.

A maioria dos casais apresenta histoincompatibilidade entre si, sugerindo que o reconhecimento desta diferença nos Ag feto-paternos seria fundamental para a manutenção da gravidez, por meio do desenvolvimento da imunotolerância materna ${ }^{6}$. A gestação, portanto, representaria importante fenômeno imunológico de tolerância: o feto (aloenxerto) e os tecidos placentários sobreviveriam, por período considerável, sem serem rejeitados, em organismo imunologicamente competente.

Os fenômenos e fatores envolvidos nos mecanismos maternos de imunossupressão e imunoestimulação ainda não foram completamente elucidados, porém alguns autores sugerem que deficiências ou desequilíbrios da resposta materna ao feto podem levar à perda gestacional e intercorrências obstétricas ${ }^{7}$.

Uma delas parece ser a pré-eclâmpsia $(\mathrm{PE})$, que é doença que ainda não tem etiologia definida. Várias são as hipóteses que tentam explicála, mas nenhuma até hoje foi completamente elucidativa.

Verificou-se que a PE é mais freqüente em pacientes primigestas, nas multigestas em que houve troca de parceiro, nas gestações resultantes de inseminação artificial com sêmen de doador e também que períodos mais longos de co-habitação sexual sem o uso de contraceptivos de barreira parecem estar inversamente relacionados à incidência de doença hipertensiva induzida pela gravide $z^{8}$.

Estas observações serviram de provas circunstanciais e evidência epidemiológica de que o mecanismo imunológico está envolvido na fisiopatologia da $\mathrm{PE}$, e que provavelmente algum fator aloimune seria o responsável pela deficiência ou desequilíbrio da resposta materna ao concepto.

Vários fatores parecem estar implicados na reação aloimune. A função das células T é dependente da identificação apropriada de grupo de marcadores de superfície celular denominados antígenos dos leucócitos humanos (HLA). Esses antígenos estão envolvidos no desencadeamento da resposta imune, pois são essenciais para o reconhecimento do que é próprio (self) ou estranho ao organismo. Os genes que promovem a produção destes determinantes antigênicos estão localizados no braço curto do cromossomo 6 e formam o complexo principal de histocompatibilidade $(\mathrm{MHC})^{9}$. Os genes da classe I codificam os 
antígenos HLA A, B e C que são encontrados em todas as células nucleadas do organismo. São os antígenos envolvidos no reconhecimento de elementos estranhos, nas respostas de rejeição a transplantes e em respostas citotóxicas dirigidas às células infectadas por vírus. Os da classe II codificam os antígenos HLA-DR, DQ e DP, que estão expressos em linfócitos $\mathrm{B}$, macrófagos, em algumas células $\mathrm{T}$ ativadas, células dendríticas e de Langerhans. Estes antígenos regulam a qualidade e a intensidade da resposta imune ${ }^{10}$.

Para o reconhecimento do Ag estranho ao organismo, as células T helper (CD4) necessitam dos Ag HLA de classe II, ao passo que as células T citotóxicas (CD8) necessitam dos Ag de classe I para se tornarem efetoras. Já as células NK (natural killer) atuam independentemente dos Ag HLA.

A gravidez tem várias semelhanças com indução de tolerância a aloenxerto, em que certo grau de tolerância a moléculas HLA estranhas é importante para a sobrevivência do enxerto. Marti e Herrmann ${ }^{11}$ investigaram se a exposição contínua e regular do trato genital feminino aos Ag espermáticos determinaria a redução de $\mathrm{PE}$ e observaram que as mulheres que utilizavam métodos contraceptivos de barreira, sem exposição da vagina ao fluido seminal, apresentavam maior probabilidade de desenvolver PE.

Explicaram tal observação pela reação alogênica provocada na mulher pelos antígenos contidos no esperma depositado na vagina. Além disso, é conhecido que a mucosa oral é local excelente para absorção de antígenos e desencadeamento de resposta, e que esta via de exposição induz tolerância aos mesmos ${ }^{12}$.

Considerando que a falha no mecanismo de tolerância pode estar envolvida na etiologia da $\mathrm{PE}$ e que a mucosa oral é local indicado para indução de tolerância, foram desenvolvidos estudos para avaliação da influência do hábito sexual no desenvolvimento da $\mathrm{PE}^{7}$. Os resultados obtidos sugerem que a prática do sexo oral pode ter efeito protetor sobre a ocorrência de PE.

O AER e a PE são intercorrências obstétricas associadas a fatores epidemiológicos comuns e que parecem apresentar fatores etiopatogênicos semelhantes. As alterações de ordem aloimunológica poderiam, portanto, ter papel importante na fisiopatologia das duas condições clínicas. Assim como na PE, os distúrbios no mecanismo de tolerância materna também podem estar envolvidos no desenvolvimento do AER. O AER seria a expressão mais precoce e máxima de rejeição e as diferentes formas de apresentação clínica da $\mathrm{PE}$, as formas tardias, intermediárias e mais brandas.
Considerando o exposto, nos propusemos por meio deste estudo a averiguar se diferentes formas de atividade sexual, vaginal e oral, com ou sem exposição ao ejaculado, interferem na ocorrência de abortamento recorrente.

\section{Pacientes e Método}

Foi realizado estudo caso-controle, desenvolvido no Departamento de Obstetrícia da UNIFESP, englobando mulheres atendidas pelo Setor de Aborto Habitual e as que procuraram Pronto-Atendimento do Hospital São Paulo - UNIFESP. A coleta de dados foi realizada entre maio de 2000 e abril de 2003.

Para a seleção de indivíduos foram submetidas à investigação 357 pacientes que aceitaram participar do estudo após terem recebido esclarecimento sobre o trabalho e terem lido e assinado termo de consentimento livre e esclarecido. As pacientes que apresentavam história de perdas gestacionais anteriores foram selecionadas, com a presença da pesquisadora, por ordem de atendimento, no Setor de Aborto Habitual. As mulheres que referiam história obstétrica normal foram selecionadas, com a presença da pesquisadora, também por ordem de atendimento no ProntoAtendimento do Departamento de Obstetrícia.

Foram definidos dois grupos: grupo caso, constituído de 116 mulheres com antecedente obstétrico de dois ou mais abortamentos espontâneos, sem a ocorrência de gestação prévia com mais de 22 semanas, e o grupo controle, com 241 mulheres cujo antecedente obstétrico mostrasse uma ou mais gestações a termo com filho vivo e sem a história de abortamentos.

Os critérios de exclusão para os grupos caso e controle foram pacientes com diagnóstico prévio ou atual de doença que pudesse, direta ou indiretamente, ser responsável por perdas gestacionais: lúpus eritematoso sistêmico; sindrome de anticorpos antifosfolipides; diabete melito; tiropatias; hipertensão arterial; anormalidades uterinas; anormalidades cromossômicas em um dos pais; pessoas tabagistas, alcoólatras, usuários de drogas; pacientes com diagnóstico atual de doenças sexualmente transmissiveis e infecto-contagiosas: sífilis, rubéola, citomegalovírus, toxoplasmose, HIV; história de quadros alérgicos como asma brônquica, atopias, dermatites de contato; pacientes que já foram transfundidas com sangue e/ou seus derivados; as com parceiro consangüineo e as com etiologia esclarecida dos abortos recorrentes. 
Para a coleta dos dados foi aplicado às participantes dos grupos caso e controle questionário no qual foram assinaladas algumas características de antecedentes clínicos, obstétricos e sexuais da mulher. O local de aplicação respeitou a privacidade das interrogadas, tendo sido garantido sigilo sobre sua participação.

Todas as participantes foram questionadas por uma mesma pesquisadora, que recebeu treinamento de abordagem às mulheres, por psicóloga especializada no trabalho com pacientes com distúrbios sexuais.

Apuramos o número de parceiros com os quais a mulher manteve relações sexuais no decorrer de sua vida. Consideramos as pacientes que mantinham uso de preservativo masculino em todas as relações com penetração vaginal até o momento que desejaram engravidar e as que não faziam uso deste método de barreira ou o utilizavam intermitentemente. Foi investigado se a mulher praticava sexo oral com seu parceiro, considerando as que referiam ter mantido atividade sexual oral nos últimos doze meses e as que a negaram.

Identificamos as pacientes que relataram, nos últimos doze meses, atividade sexual oral com o parceiro em que sua mucosa oral entrasse em contato com o material ejaculado e as que negaram tal prática.

A presença de associação entre os grupos de estudo e os parâmetros qualitativos foi verificada pelo teste do $\chi^{2}$.

$\mathrm{Na}$ análise das variáveis quantitativas foram utilizados testes não paramétricos. A comparação entre os grupos de estudo em relação às demais variáveis quantitativas foi feita pela prova de MannWhitney para amostras independentes. Adotou-se o nivel de significância de $0,05(\alpha=5 \%)$.

Este estudo foi previamente aprovado pelo Comitê de Ética em Pesquisa da Universidade Federal de São Paulo - UNIFESP-EPM, e foi desenvolvido com mulheres que participaram voluntariamente.

\section{Resultados}

Quanto ao número de parceiros masculinos com quem a paciente referiu ter mantido relações sexuais até o momento da pesquisa, podemos verificar na Tabela 1 que $38,8 \%$ das pacientes do grupo caso e $35,7 \%$ das do grupo controle referiram ter tido somente um parceiro, não havendo diferença entre as pacientes com aborto de repetição e as com sucesso gestacional.
Tabela 1 - Número de parceiros masculinos com quem as pacientes dos grupos caso e controle mantiveram atividade sexual.

\begin{tabular}{lcccccc}
\hline Número de parceiros & \multicolumn{4}{c}{ Grupo } & \multicolumn{2}{c}{ Total } \\
& \multicolumn{2}{c}{ Casos } & \multicolumn{2}{c}{ Controles } & & \\
& $\mathbf{n}$ & $\%$ & \multicolumn{1}{c}{$\mathbf{n}$} & $\%$ & $\mathbf{n}$ & $\%$ \\
\hline Um & 45 & 38,8 & 86 & 35,7 & 131 & 36,7 \\
Dois & 27 & 23,3 & 59 & 24,5 & 86 & 24,1 \\
Três & 20 & 17,2 & 43 & 17,8 & 63 & 17,6 \\
Quatro ou mais & 24 & 20,7 & 53 & 22,0 & 77 & 21,6 \\
Total & 116 & 100,0 & 241 & 100,0 & 357 & 100,0 \\
\hline
\end{tabular}

Teste do $\chi^{2}: p=0,954$

Quanto ao uso de preservativo, podemos observar na Tabela 2 que a maior parte das pacientes dos grupos caso $(76,7 \%)$ e controle $(74,7 \%)$ não usam rotineiramente o método de barreira, e não foi observada diferença significativa entre os dois grupos.

Tabela 2 - Uso rotineiro de preservativo masculino nas pacientes dos grupos caso e controle.

\begin{tabular}{lrrrrrr}
\hline Uso rotineiro de & \multicolumn{4}{c}{ Grupo } & \multicolumn{2}{c}{ Amostra total } \\
preservativo & \multicolumn{2}{c}{ Caso } & \multicolumn{2}{c}{ Controle } & & \\
masculino & $\mathbf{n}$ & $\%$ & \multicolumn{1}{c}{$\mathbf{n}$} & $\%$ & $\mathbf{n}$ & $\%$ \\
\hline Não & 89 & 76,7 & 180 & 74,7 & 269 & 75,4 \\
Sim & 27 & 23,3 & 61 & 25,3 & 88 & 24,6 \\
Total & 116 & 100,0 & 241 & 100,0 & 357 & 100,0 \\
\hline
\end{tabular}

Teste do $\chi^{2}: p=0,774$.

Quanto à prática de sexo oral pelas pacientes, podemos apurar na Tabela 3 que no grupo caso 66 pacientes $(56,9 \%)$ o realizavam e no grupo controle, $110(45,6 \%)$ mulheres relatavam este hábito, não havendo diferença significativa entre o número de pacientes que praticava sexo oral entre os dois grupos analisados.

Tabela 3 - Prática de sexo oral nas pacientes dos grupos caso e controle.

\begin{tabular}{lrrrrrr}
\hline Prática de sexo oral & \multicolumn{4}{c}{ Grupo } & \multicolumn{2}{c}{ Total } \\
& \multicolumn{2}{c}{ Caso } & \multicolumn{2}{c}{ Controle } & & \\
& $\mathbf{n}$ & $\%$ & $\mathbf{n}$ & $\%$ & $\mathbf{n}$ & $\%$ \\
\hline Não & 50 & 43,1 & 110 & 45,6 & 160 & 44,8 \\
Sim & 66 & 56,9 & 131 & 54,4 & 197 & 55,2 \\
Total & 116 & 100,0 & 241 & 100,0 & 357 & 100,0 \\
\hline
\end{tabular}

Teste do $\chi^{2}: p=0,735$.

Observa-se na Tabela 4 que das 116 pacientes do grupo caso, $100(86,2 \%)$ negaram contato da mucosa oral com material ejaculado, ao passo que 16 $(13,8 \%)$ afirmaram que na prática do sexo oral sua 
mucosa bucal entrava em contato com o ejaculado. Das 241 pacientes do grupo controle $49(20,3 \%)$ assinalaram este contato, ao passo que $192(79,7 \%)$ o negaram. Apura-se não haver diferença significativa entre os dois grupos no que se refere ao número de pacientes que relataram contato de sua mucosa oral com o material ejaculado pelo parceiro.

Tabela 4 - Contato da mucosa oral com material ejaculado nas pacientes dos grupos caso e controle.

\begin{tabular}{lrrrrrr}
\hline \multirow{2}{*}{$\begin{array}{l}\text { Contato oral com } \\
\text { ejaculado }\end{array}$} & \multicolumn{4}{c}{ Grupo } & \multicolumn{2}{c}{ Total } \\
& \multicolumn{2}{c}{ Caso } & \multicolumn{2}{c}{ Controle } & & \\
& n & \multicolumn{1}{c}{$\mathbf{n}$} & $\%$ & \multicolumn{1}{c}{$\mathbf{n}$} & $\%$ \\
\hline Não & 100 & 86,2 & 192 & 79,7 & 292 & 81,8 \\
Sim & 16 & 13,8 & 49 & 20,3 & 65 & 18,2 \\
Total & 116 & 100,0 & 241 & 100,0 & 357 & 100,0 \\
\hline
\end{tabular}

Teste do $\chi^{2}: p=0,176$

\section{Discussão}

Existem indicações na literatura de que o padrão de atividade sexual possa influenciar a evolução da gravidez, pelo desenvolvimento de "adequação" ou "adaptação" imunológica a antígenos de origem paterna por meio do contato entre o esperma e o trato genital feminino.

Alguns investigadores demonstraram a presença de moléculas HLA classe I no líquido seminal, identificadas por método imunoenzimático, com uso de anticorpo monoclonal. Observou-se que a quantidade destas moléculas no sêmen é menor que no plasma sangüíneo ${ }^{7}$.

As moléculas HLA clássicas A e B estão presentes no plasma seminal. Entretanto, outras moléculas classe I, como, por exemplo, a HLA-C clássica e as HLA I não clássicas (HLA-E, F e G), não foram demonstradas em plasma seminal, embora Koelman et al. ${ }^{7}$ tenham referido que estas últimas têm baixa imunogenicidade e pouca expressão, não sendo importantes para indução de imunotolerância.

Até o momento não está definitivamente estabelecido se a tolerância aos Ag MHC clássicos paternos tem importância para a sobrevida fetal. O trofoblasto não expressa os Ag HLA-A e B e tem expressão transitória e restrita a alguns sítios do Ag HLA-C ${ }^{13}$. Entretanto, a indução de aloanticorpos pela gravidez indica que o sistema imunológico materno é confrontado com os antígenos HLA-A e $\mathrm{B}$ do pai presentes no concepto. É possivel que a tolerância originalmente induzida por antígenos HLA-A e B solúvel abranja Ag HLA não clássicos expressos no trofoblasto ${ }^{14}$.
Até o momento a função das moléculas HLA solúvel no esperma permanece desconhecida. Acredita-se que elas devam ter papel na proteção do espermatozóide contra o sistema imune materno, embora espermatozóides não expressem moléculas HLA em suas membranas ${ }^{13}$. Alguns autores sugerem que a presença de HLA solúvel no plasma seminal deve representar o papel paterno na indução de tolerância materna ao feto, o que poderia indicar que a indução de tolerância pode ter lugar por exposição vaginal ou oral.

O contato materno com o sêmen representaria caminho simples e direto para exposição do endométrio a estes antígenos ${ }^{7}$. No entanto, este aspecto é muito controverso, pois outros pesquisadores não detectaram estes Ag no sêmen ${ }^{10}$. Tremellen et al. ${ }^{15}$ observaram que a deposição do sêmen no trato genital feminino provocaria uma cascata de eventos moleculares e celulares que se assemelharia a uma resposta inflamatória. Dekker ${ }^{16}$ refere que algum grau de reação inflamatória é importante e benéfica para o desenvolvimento da gravidez, pois ele seria o fator que desencadearia o início do processo de vasodilatação.

Robertson et al. ${ }^{17}$ sugeriram que o fator seminal desencadeador parece ser o fator transformador de crescimento, derivado da vesícula seminal (TGF $\beta 1$ ). Estes autores demonstraram que a inseminação intra-uterina de TGF $\beta 1$ resulta em aumento de granulócitos e monócitos, além de iniciar leucocitose endometrial. Ao iniciar esta reação inflamatória, o TGF $\beta 1$ aumentaria a habilidade de processar Ag paternos contidos no ejaculado, além de iniciar uma forte reação de desvio para resposta imunológica Th2. Isto inibiria a indução de resposta Th1 contra o concepto semi-alogênico, o que poderia se associar a desenvolvimento placentário e fetal deficiente.

Em que pese a estas considerações, ao analisarmos nossos resultados, observamos quanto ao número de parceiros com quem as mulheres mantiveram atividade sexual no decorrer de sua vida, que mais da metade das mulheres referiram contato sexual com dois ou mais parceiros até o momento da pesquisa, tanto as que apresentavam história de AER como as com história de sucesso gestacional, não havendo diferença estatisticamente significante entre o número de parceiros referido por elas.

Marti e Herrmann ${ }^{11}$ foram os primeiros a relatar que o número de parceiros com quem a mulher co-habitava antes da gravidez era cerca de três vezes maior entre as que evoluíam com gestação normal do que nas com PE, tendo concluído que estes achados explicavam a razão da maior incidência de PE em adolescentes. Como existe 
no esperma expressão de Ag HLA solúveis, e estes seriam responsáveis pela indução de tolerância, seria presumivel que a mulher que entrasse em contato com esperma de diferentes parceiros teria maior oportunidade de desenvolver imunotolerância e assim ter condições de apresentar evolução normal de uma gravidez.

Nossos dados contrariam esta hipótese em relação às pacientes com aborto de repetição, levando-nos a pensar que a imunotolerância promovida pelo contato com diferentes Ag do esperma de parceiros diferentes não protege a mulher da perda gestacional na forma de aborto.

Em relação ao uso de preservativo masculino, nossos achados sugerem que a exposição ou não da mucosa vaginal ao esperma do parceiro não alterou a ocorrência de aborto de repetição. KlonoffCohen et al. ${ }^{18}$, entretanto, ao estudar a história contraceptiva de mulheres com e sem PE, apurou risco 2,4 vezes maior de $\mathrm{PE}$ nas usuárias de contraceptivos que impediam a exposição do endométrio ao ejaculado (métodos de barreira, espermicidas) do que nas que não usavam este tipo de método. Segundo o autor, quando não há barreira o esperma entraria em contato com o endométrio e quando há barreira nenhum esperma ou só os espermatozóides não viáveis entrariam em contato com o endométrio e o sistema imune materno não seria exposto aos Ag paternos, não havendo desenvolvimento da imunotolerância.

Também discordando de nossas observações, Robillard et al. ${ }^{8}$ referiram que o padrão de atividade sexual poderia influenciar a resposta imunológica materna a Ag de origem paterna pelo contato entre o esperma e o trato genital feminino, fenômeno que poderia ser alterado pelo uso dos métodos contraceptivos de barreira.

Gratacós et al. ${ }^{19}$, analisando a evolução da gravidez de primigestas, observaram que a exposição sexual prolongada, anterior à concepção, estava relacionada à baixa incidência de $\mathrm{PE}$. Dekker $^{16}$ sugeriu a partir desta observação que a exposição por tempo prolongado ao esperma poderia ser fator importante para o sucesso da implantação humana. Comenta que isto faz sentido quando se pensa que a mulher é um dos únicos mamíferos que fica exposto ao sêmen do parceiro inúmeras vezes antes da concepção. O autor sugere que, em uma perspectiva evolutiva, pode-se questionar se a indução de tolerância a Ag paternos por repetidas exposições ao esperma tem vantagens reprodutivas, talvez por promover implantação e sobrevivência de embriões concebidos em longos relacionamentos.

Por outro lado, Morcos et al. ${ }^{20}$ acharam que em primíparas a duração curta de co-habitação estava associada apenas com redução discreta, não significativa de risco de PE. Hall et al. ${ }^{21}$ também não detectaram relação entre o tempo de atividade sexual com exposição da mucosa vaginal e o desencadeamento de PE.

A análise da prática de sexo oral como fator que pudesse influenciar a história obstétrica era nosso principal aspecto de pesquisa, por supor que a exposição ao esperma, portador de Ag HLA paternos, da mucosa oral da mãe, considerada como local de boa absorção e indução de tolerância, poderia determinar resposta imunológica responsável pela evolução da gravidez, pois ela tem muita semelhança com a evolução de enxerto transplantado, em que certa tolerância a moléculas HLA estranhas é fundamental para sua sobrevida.

Nossos achados revelaram não haver diferença significativa entre o número de casais que praticavam sexo oral, entre as pacientes com história de aborto de repetição e as que apresentavam sucesso gestacional, sendo que praticamente a metade das mulheres referiram esta atividade. De modo semelhante não apuramos diferença significativa entre os dois grupos no que se refere ao número de pacientes que relataram contato de sua mucosa oral com o material ejaculado pelo parceiro, sendo que cerca de 15 a $20 \%$ delas o faziam. Discordando de nossos achados em pacientes com aborto de repetição, Koelman et al. ${ }^{7}$ observaram que entre as primiparas com $\mathrm{PE}$ somente $44 \%$ tinham praticado sexo oral com seu parceiro antes da gravidez atual, entretanto entre as do grupo controle $82 \%$ referiam tal prática. Eles também apuraram que entre primíparas com PE somente $17 \%$ referiam ter praticado sexo oral com exposição de mucosa oral ao esperma, sendo que $48 \%$ das do grupo controle referiam tal prática. Estes autores concluíram que a exposição aos Ag paternos pela prática do sexo oral repetidas vezes protegia a mulher de desenvolver a doença durante a gravidez. A hipótese formulada por eles seria que moléculas de HLA clássico, A e B, presentes em plasma seminal poderiam, pela exposição à mucosa oral, induzir estado de tolerância ao concepto.

Para tentar explicar os achados discordantes quanto à importância da exposição da mucosa oral ao sêmen em nossa população, é importante considerar que o nível e os tipos de antígenos HLA expressos no esperma podem ser diferentes entre os indivíduos, e que é possível que os parceiros das pacientes com aborto de repetição apresentem menor nível de antígenos HLA no sêmen do que os parceiros das mulheres de nosso grupo controle. Assim, embora as pacientes tenham conta- 
to oral com líquido seminal não há indução de tolerância porque a exposição é insuficiente, pelo baixo nível de antígenos.

Finalizando, a análise das variáveis estudadas nos leva a concluir que nossos resultados não confirmam a hipótese de que o comportamento sexual tenha influência sobre a ocorrência do aborto espontâneo de repetição como parece acontecer na PE. Uma das explicações plausiveis seria que o modelo proposto para PE não possa ser transposto para abortamento espontâneo de repetição, pois a $\mathrm{PE}$ seria a exacerbação de resposta imune inespecífica e no abortamento haveria ativação preferencial de resposta imune de padrão Th 1 na qual as células NK, os Ag HLA-G e interferon- $\gamma$ (IFN- $\gamma$ ) teriam papel determinante.

É nossa opinião que cada vez mais se firma a hipótese de que o quadro de abortamento espontâneo de repetição tenha etiologia multifatorial, e que o aspecto imunológico merece continuar sendo investigado nesta entidade, talvez com diferentes abordagens.

\section{ABSTRACT}

Purpose: to evaluate whether oral and vaginal sex practice, with or without exposure to semen, decrease the occurrence of recurrent spontaneous abortion.

Method: this was a case-control study carried out between May 2000 and April 2003. A questionnaire was applied analyzing the clinical, obstetric and sexual history of women, who were divided into two groups: a case group comprised 116 patients with a history of at least two spontaneous abortions, without previous pregnancy longer than 22 weeks, and a control group that included 241 women with history of one or more term pregnancies with live birth and no miscarriage. The analyzed variables included the number of sexual partners, condom use, oral sex practice, and the exposure of female oral mucosa to semen.

Results: in the control group $38.8 \%$, and in the patients group $35.7 \%$ of the women had only one partner. In both groups about $75 \%$ of the women reported that the partners did not use condom. Approximately 55\% of the women of both groups referred oral sex practice, and $13.8 \%$ of those with recurrent abortion and $20.3 \%$ with a history of successful pregnancies had oral mucosa exposed to semen. There was no difference between the patients with recurrent abortion and women with successful pregnancies regarding number of sexual partners, use of condom, practice of oral sex, and exposure of oral mucosa to the partner's semen.

Conclusion: our results did not confirm the hypothesis that sexual behavior influences the occurrence of spontaneous abortion.

KEYWORDS: Recurrent spontaneous abortion. Alloimmunity. Sexual behavior.

\section{Referências}

1. Stirrat GM. Recurrent miscarriage I. Definition and epidemiology. Lancet 1990; 336:673-5.

2. Coulam CB. Epidemiology of recurrent spontaneous abortion. Am J Reprod Immunol 1991; 26:23-7.

3. Clifford K, Rai R, Watson H, Regan L. An informative protocol for the investigation of recurrent miscarriage: preliminary experience of 500 consecutive cases. Hum Reprod 1994; 9:1328-32.

4. Christiansen OB. A fresh look at the causes and treatments of recurrent miscarriage, especially its immunological aspects. Hum Reprod Update 1996; 2:271-93.

5. Medawar PB. Some immunological and endocrinological problems raised by the evolution of viviparity in vertebrates. Symp Soc Exp Biol 1953; 7:320- 38 .

6. Koelman CA, Ensink W, Mulder A, Tanke J, Doxiadis II, Claas FH. Anti-HLA antibodies interfere in the detection of soluble HLA class I molecules. Hum Immunol 1999; 60:414-23.

7. Koelman CA, Coumans AB, Nijman HW, Doxiadis II, Dekker GA, Claas FH. Correlation between oral sex and a low incidence of preeclampsia: a role for soluble HLA in seminal fluid? J Reprod Immunol 2000; 46:155-66.

8. Robillard PY, Hulsey TC, Périanin J, Janky E, Miri $\mathrm{EH}$, Papiernik E. Association of pregnancy-induced hypertension with duration of sexual cohabitation before conception. Lancet 1994; 344:973-5.

9. Pereira MD, Menegoci JC. Mecanismos imunológicos relacionados ao aborto recorrente. Femina 2002; 30:175-80.

10. Choudhury SR, Knapp LA. Human reproductive failure II: immunogenetic and interacting factors. Hum Reprod Update 2001; 7:135-60.

11.Marti JJ, Herrmann U. Immunogestosis: a new etiologic concept of "essential" EPH gestosis, with special consideration of the primigravid patient; preliminary report of a clinical study. Am J Obstet Gynecol 1977; 128:489-93.

12.Brandtzaeg P. History of oral tolerance and mucosal immunity. Ann N Y Acad Sci 1996; 778:1-27.

13.Schaller J, Glander HJ, Ladusch M, Westhoff U, Grosse-Wilde H. Lack of HLA-molecules on human spermatozoa and in seminal plasma. Andrologia 1993; 25:77-81.

14.Yang L, DuTemple B, Gorczynski RM, Levy G, Zhang L. Evidence for epitope spreading and active suppression in skin graft tolerance after donorspecific transfusion. Transplantation 1999; 67:1404-10. 
15.Tremellen KP, Seamark RF, Robertson SA. Seminal transforming growth factor $\beta 1$ stimulates granulocyte-macrophage colony-stimulating factor production and inflammatory cell recruitment in the murine uterus. Biol Reprod 1998; 58:1217-25.

16.Dekker GA. Oral tolerization to paternal antigens and preeclampsia. Am J Obstet Gynecol 1996; $174: 450$.

17. Robertson SA, Ingman WV, O'Leary S, Sharkey DJ, Tremellen KP. Transforming growth factor $\beta$ - a mediator of immune deviation in seminal plasma. J Reprod Immunol 2002; 57:109-28.

18.Klonoff-Cohen HS, Savitz DA, Cefalo RC, McCcann MF. An epidemiologic study of contraception and preeclampsia. JAMA 1989; 262:3143-7.
19. Gratacós E, Torres PJ, Cararach V, Quinto L, Alonso PL, Fortuny A. Does the use of contraception reduce the risk of pregnancy-induced hypertension? Hum Reprod 1996; 11:2138-41.

20.Morcos RN, Bourguet CC, Gill PP, et al. Pregnancyinduced hypertension and duration of sexual cohabitation. J Reprod Med 2000; 45:207-12.

21.Hall GH, Noble WL, Lindow SW, Masson EA. Longterm sexual co-habitation offers no protection from hypertensive disease of pregnancy. Hum Reprod 2001; 16:349-52.

Recebido em: 25/11/2003 Aceito com modificações em: 19/1/2004 